\title{
Metabolic Syndrome During Pregnancy: Prevalence and Determinants Among Pregnant Women Followed-Up at the Dschang District Hospital, West Region of Cameroon
}

\author{
Solange Dabou (1)', Nadine Sylvie Ongbayokolak ${ }^{1,2}$, Leonard Fonkeng Sama', Emerveline Matene Foking', \\ Nadine Mélaine Kamdom', Phélix Bruno Telefo' \\ 'Department of Biochemistry, University of Dschang, Dschang, Cameroon; ${ }^{2}$ Department of Biomedical Analyses, Dschang District Hospital, Dschang, \\ Cameroon \\ Correspondence: Phélix Bruno Telefo, Department of Biochemistry, University of Dschang, PO Box 67, Dschang, Cameroon, Tel +237 677204267, \\ Fax+237243691506, Email bphelix@yahoo.co.uk
}

\begin{abstract}
Purpose: Metabolic syndrome (MS) during pregnancy constitutes a serious threat to the mother and child health that will shortly become a major public health issue, especially in developing countries. However, in Cameroon, epidemiological data on MS during pregnancy are still scarce. The aim of this study was to determine the prevalence and determinants of MS among pregnant women followed-up at the Dschang District Hospital (DDH), in the west region of Cameroon.

Patients and Methods: This study was a hospital based cross-sectional study, carried out among pregnant women followed-up at the antenatal care unit of the DDH, from September 2019 to June 2020. Participants were assessed on sociodemographic, lifestyle parameters, and dietary habits using standardized and structured questionnaires. Anthropometric parameters, blood pressure, and biochemical markers were measured using standard procedures. Metabolic syndrome was diagnosed using the HNLBI/AHA definition, modified for pregnant women by Chatzi et al. A participant was recorded as having MS if presenting at least three of the following criteria: Pre-gestational BMI $>30 \mathrm{~kg} / \mathrm{m} 2$; triglycerides $\geq 150 \mathrm{mg} / \mathrm{dl}$; HDL cholesterol $<50 \mathrm{mg} / \mathrm{dl} ; \mathrm{SBP} \geq 130 / \mathrm{DBP} \geq 85 \mathrm{~mm} / \mathrm{Hg}$; and fasting blood glucose $\geq 100 \mathrm{mg} / \mathrm{dl}$.
\end{abstract}

Results: Six hundred and four (604) pregnant women were included in the study. The prevalence of MS was 17.88\% (95\% CI: 15.03-21.14) and its most frequent individual components were low levels of HDL-cholesterol (66.23\% (95\% CI: 62.36-69.88)) and hypertriglyceridemia (28\% (95\% CI: 54.31-62.15)). Grand multiparous shows a higher risk of presenting MS (OR:3.06, 95\% CI: 1.24-7.12; $\mathrm{p}=0.011)$ compared to nulliparous. Pregestational BMI appears to be the best predictor of MS during pregnancy even after adjustment on age, parity, lifestyle and dietary habits (OR: 46.46, 95\% CI: $15.58-138.49 ; p<0.0001$ ).

Conclusion: The prevalence of MS on pregnant women in the Dschang health district is $17.88 \%$ (95\% CI: 15.03-21.14) and its major determinant is pre-gestational obesity. This work provides quality preliminary data for the design and improvement of prevention strategies.

Keywords: metabolic syndrome, pregnancy, risk factors, Dschang health district

\section{Introduction}

Metabolic syndrome (MS) is a complex set of interconnected cardiovascular diseases and type II diabetes risk factors that occur more often together than by chance alone. ${ }^{1}$ Metabolic abnormalities related to MS include obesity, impaired glucose tolerance, dyslipidemia and elevated blood pressure, all related to chronic low-grade inflammation and alterations of insulin sensitivity. ${ }^{2} \mathrm{MS}$ is a common and serious health issue, both in developed and developing countries. Its prevalence is reaching astounding proportions all around the world. About one third of US adults have MS. ${ }^{2}$ Its prevalence varies from $20.41 \%$ to $39.68 \%$ in China and from $24 \%$ to $33 \%$ in India. ${ }^{3,4}$ Comparable tendency is observed in Africa, with a prevalence of MS varying across countries and depending on the diagnosis criteria considered. Authors 
reported a prevalence of $34.6 \%$ in Kenya, $19.1 \%$ in Uganda, $34.89 \%$ in Ethiopia, $42.6 \%$ in South Africa. ${ }^{5-8}$ In Cameroon, the prevalence of MS is reported to be $32.45 \%$ in the west region of the country, based on the IDF criteria. ${ }^{9}$

The relatively high prevalence of MS observed in Africa and especially in Cameroon shows a strong predominance among females. Indeed, women seem to be more affected by MS and its components than men, regardless of age and other risk factors. $^{5,7-9}$ Determinants of that feminine predominance of MS may include socio-cultural parameters, metabolic variations related to the reproductive cycle and multiple pregnancies. ${ }^{5,10}$ When occurs during pregnancy, MS constitutes a serious threat to the mother and child's health. ${ }^{10}$ Few studies have highlighted a link between MS in early pregnancy or its individual features and adverse maternal and fetal pregnancy but also perinatal outcomes, including gestational diabetes, preterm birth, neural tube defects and increase risk for the newborn to develop obesity, MS or type 2 diabetes later in life. ${ }^{11-14}$ The consequences of MS during pregnancy thus affect not only the pregnant mother but also the child to be born. MS during pregnancy therefore has to become a special concern to be addressed, in other to prevent maternal and fetal complications, as well as a future expansion of its incidence. However, there is still not a consensus on the definition of MS during pregnancy, for the metabolic changes that occur all along normal pregnancy overlap MS related disorders. ${ }^{13,15}$ Existing definitions with cut-off points adapted to pregnancy are available and may be used for diagnosis purpose, but in a preventive perspective, a set of criteria with higher sensitivity may be necessary. ${ }^{13,15}$ In Cameroon, as in many developing countries, there are still low epidemiological data on MS during pregnancy, with a lack of information on its determinants and potential targets for efficient prevention strategies. Better attention on the diagnosis of MS during pregnancy could help identify phenotypes of women presenting higher risk of adverse pregnancy outcomes and cardio metabolic conditions later in life, but also newborns with predispositions to childhood obesity and MS. ${ }^{11,15}$

The aim of this study, thus, is to determine the prevalence and determinants of MS among pregnant women of the Dschang health district in the west region of Cameroon.

\section{Materials and Methods}

\section{Ethical Considerations}

The study received approval from the Dschang health district and Dschang district hospital authorities. The "Cameroon Bioethics Initiative Ethics Review and Consultancy Committee (CAMBIN/ERCC)" approved the study protocol with a research ethical clearance at the number CBI/471/ERCC/CAMBIN. Each step of the study was realized in accordance with the Helsinki declaration, and all participants provided signed informed consent.

\section{Study Design}

This study was a hospital based cross-sectional study, conducted from September 2019 to June 2020, among pregnant women attending antenatal care at the Dschang District Hospital (DDH), in the Dschang Health District (DHD), west region of Cameroon.

\section{Sample Size and Sampling Method}

The sample size was calculated using the Statcalc tool of the software Épi info version 7.2.3.1, assuming an estimated prevalence of MS of 7.39\% in the $\mathrm{DDH},{ }^{16}$ a $5 \%$ acceptable margin of error, an estimated design effect of 5 and a $95 \%$ confidence level. The minimum sample size was thus of 520 participants. A percentage of imponderables of $10 \%$ was added to the model for a final minimal sample size of 572 participants. Selection of participants was made by exhaustive sampling of all the pregnant women meeting selection criteria.

\section{Participants}

We included in the study, apparently healthy Cameroonian pregnant women aged from 16 to 45 years of any pregnancy age, coming for antenatal consultation at the DDH. Pregnant women with recorded diabetes mellitus, cardiovascular diseases (For, the definition of MS during pregnancy considered in the study is not applicable for pregnant women with previously diagnosed diabetes mellitus or cardiovascular diseases.) and mental illness were not included in the study. Participants with multiple pregnancies detected after the first ultrasound scan were excluded from the study sample. 


\section{Administration of the Questionnaire}

The study questionnaire was organized in three different parts: A survey form inspired from the WHO STEPS instrument for chronic diseases surveillance, recording personal and family history of chronic diseases as well as alcohol and tobacco use; A modified version of the Ricci and Gagnon questionnaire evaluating participants' level of physical activity and a food frequency questionnaire, recording dietary habits of participants. Individual questionnaires were filled by each participant, through a face-to-face interview with the principal investigator.

\section{Determination of Anthropometric Parameters}

Height was measured with a height gauge to the nearest $0.1 \mathrm{~cm}$. Weight was measured using a scale $\left(\mathrm{SECA}^{\circledR}\right)$ to the nearest $0.1 \mathrm{~kg}$. Pre-pregnancy weight was collected when available from medical records or self-reported by participants. Body Mass Index (BMI) was calculated using the Quételet's formula: BMI $=$ Weight $(\mathrm{kg}) / \mathrm{Height}^{2}(\mathrm{~m})$ and expressed as $\mathrm{kg} / \mathrm{m}^{2}$. A BMI $\geq 25$ defined overweight and a BMI $\geq 30$ defined obesity. ${ }^{17}$

\section{Blood Pressure Measurement}

Blood pressure (BP) was measured with an Automatic Blood Pressure Monitor with Heart Sense (One Plus Healthcare ${ }^{\circledR}$ FT-11B) in a sitting position after at least 10 minutes of rest and two measurements were taken after 5 minutes intervals. The average of the two measurements was used to assess blood pressure level.

\section{Blood Sampling}

A sample of $5 \mathrm{~mL}$ of blood was collected on dry tubes by venipuncture on the antecubital fossa from each participant after overnight fasting. The serum was obtained by centrifugation at $3500 \mathrm{~g}$ during 5 minutes and aliquots were frozen at $-20^{\circ} \mathrm{C}$ previous to biochemical analyses.

\section{Biochemical Analyses}

Fasting blood glucose was directly measured by reflectometry on capillary blood (collected at the participant's fingertip) using a glucometer (OnCall Sharp ${ }^{\circledR}$ ) and glucose test tips. The concentration of serum total cholesterol, HDL-cholesterol and triglycerides were measured by the standard enzymatic spectrophotometric method, ${ }^{18,19}$ using Labkit ${ }^{\circledR}$ Diagnostic kits. LDL-cholesterol concentrations were assessed using Friedewald's formula for triglycerides levels lower than $350 \mathrm{mg} / \mathrm{dl} .{ }^{20}$ Atherogenicity index was defined as the ratio Total cholesterol/HDL-cholesterol. All specimens and reagents were handled according to the manufacturer instructions.

\section{Diagnosis of Metabolic Syndrome}

Metabolic syndrome was diagnosed using the HNLBI/AHA and NECP ATP III definitions, modified for pregnant women by Chatzi et al ${ }^{12,13}$ A participant was recorded as having MS if presenting at least three of the following criteria: Pre-gestational BMI $>30 \mathrm{~kg} / \mathrm{m} 2$; triglycerides $\geq 150 \mathrm{mg} / \mathrm{dl}$; HDL cholesterol $<50 \mathrm{mg} / \mathrm{dl} ; \mathrm{SBP} \geq 130 / \mathrm{DBP} \geq 85 \mathrm{~mm} / \mathrm{Hg}$; and fasting blood glucose $\geq 100 \mathrm{mg} / \mathrm{dl}$.

\section{Statistical Analyses}

Data treatment was performed using the softwares Epi info ${ }^{\text {TM }}$ 7.2.3.1 for Microsoft Windows ${ }^{\circledR}$ and R.4.0.2 for Microsoft Windows ${ }^{\circledR}$. For descriptive statistics, categorical variables are presented as frequency distribution tables and continuous variables as mean \pm standard deviation (SD). The comparison of MS prevalence among potential determinants was performed using the Pearson Chi-squared test and means of biological parameters were compared among participants with MS and participants without MS using the Student's $t$-test. Generalized linear models (binary logistic regression) were performed to predict MS and identify its determinants. The level of significance for all inferential statistics was set at $p<0.05$.

\section{Results}

A total of 621 pregnant women were included in the study. After verification of exclusion criteria, a final sample of 604 pregnant women was considered. Their sociodemographic and obstetric characteristics are summarized in Table 1. The 
Table I Sociodemographic and Obstetric Characteristics of the Study Population

\begin{tabular}{|c|c|c|}
\hline Parameter & & Frequency in \% (n) \\
\hline \multirow[t]{5}{*}{ Age (Years) } & \multicolumn{2}{|c|}{ Mean \pm SD: $26.75 \pm 5.57$} \\
\hline & $<20$ & $6.95(42)$ \\
\hline & [20-30] & $61.75(373)$ \\
\hline & [30-40] & $28.97(175)$ \\
\hline & $\geq 40$ & $2.32(14)$ \\
\hline \multirow[t]{4}{*}{ Marital status } & Single & $35.43(214)$ \\
\hline & Divorced & $0.66(4)$ \\
\hline & Cohabitation & $8.61(52)$ \\
\hline & Married & $55.30(334)$ \\
\hline \multirow[t]{4}{*}{ Level of education } & No formal education & $2.32(14)$ \\
\hline & Primary & $6.13(37)$ \\
\hline & Secondary & $45.36(274)$ \\
\hline & Higher education & $46.19(279)$ \\
\hline \multirow[t]{4}{*}{ Stage of the pregnancy } & \multicolumn{2}{|c|}{ Mean \pm SD: $22.78 \pm 9.20$ (weeks) } \\
\hline & Ist Trimester & $25.83(156)$ \\
\hline & 2nd Trimester & $42.22(255)$ \\
\hline & 3rd Trimester & $31.95(193)$ \\
\hline \multirow[t]{4}{*}{ Parity } & Nulliparous & $50.09(276)$ \\
\hline & Primiparous & $19.42(107)$ \\
\hline & Multiparous & $25.4 I(140)$ \\
\hline & Grand multiparous & $5.08(28)$ \\
\hline
\end{tabular}

Abbreviations: (n), Absolute frequencies; SD, Standard deviation.

mean age was $26.75 \pm 5.57$ and $61.75 \%$ of participants were aged between $20-30$ years. Most participants were married $(55.30 \%)$ with secondary $(45.36 \%)$ or higher $(46.19 \%)$ education level achieved. The mean gestational age was $22.78 \pm$ 9.20 weeks and half of the study population (50.09\%) comprised nulliparous pregnant women. Concerning Pregestational BMI, 29.80\% (180) had a normal BMI and 42.88\% (259) were overweight before pregnancy.

Table 2 shows the prevalence of metabolic syndrome and its individual components in the study population. One hundred and height pregnant women were diagnosed positive to metabolic syndrome for a prevalence of $17.88 \%$ (95\% CI: $15.03-21.14)$. The most frequent individual component of MS was low levels of HDL-cholesterol, with a prevalence of $66.23 \%$ (95\% CI: 62.3669.88), followed by hypertriglyceridemia with a prevalence of 58.28\% (95\% CI: 54.31-62.15). A multivariate binary logistic regression model was performed to identify predictors of MS among its individual components. The results presented in Table 2 indicate that pre-gestational BMI (OR: 1.36, 95\% CI: 1.28-1.46; $p<0.0001)$ and HDL-cholesterol blood level (OR: 0.96, 95\% CI: $0.94-0.98 ; p<0.0001$ ), are the key components of MS during pregnancy.

Table 2 Prevalence of MS and Its Individual Components and Multivariate Logistic Regression Model to Predict MS by Its Individual Components

\begin{tabular}{|c|c|c|c|c|c|}
\hline \multicolumn{3}{|l|}{ Prevalence } & \multicolumn{3}{|c|}{ Multivariate Logistic Regression Model } \\
\hline Components & Prevalence (\%) & $95 \% \mathrm{Cl}$ & Components & OR $(95 \% \mathrm{Cl})$ & $p$ \\
\hline Pre-pregnancy obesity & 27.32 & $23.92-31.01$ & Pre-pregnancy BMI & $1.36(1.28-1.46)$ & $<0.0001$ \\
\hline Elevated blood pressure & 11.92 & $9.57-14.75$ & SBP & I $(0.99-1.01)$ & 0.658 \\
\hline High fasting blood glucose & 4.97 & $3.50-7.00$ & DBP & $1.04(1.01-1.07)$ & 0.001 \\
\hline Hypertriglyceridemia & 58.28 & $54.31-62.15$ & Blood glucose level & $1.02(1.00-1.05)$ & 0.025 \\
\hline Low HDL-cholesterol & 66.23 & $62.36-69.88$ & Triglycerides & $\mathrm{I}(\mathrm{I} .00-1.0 \mathrm{I})$ & $<0.0001$ \\
\hline Metabolic syndrome & 17.88 & $15.03-21.14$ & HDL-cholesterol & $0.96(0.94-0.98)$ & $<0.0001$ \\
\hline
\end{tabular}

Abbreviations: OR, Odd ratio; $\mathrm{Cl}$, Confidence interval; SBP, Systolic blood pressure; DBP, Diastolic blood pressure. 
The cardio metabolic profile of pregnant women included in this study is shown in Table 3. The mean values of pregestational Body Mass Index (BMI), systolic blood pressure (SBP), diastolic blood pressure (DBP), blood glucose level, triglycerides, HDL-cholesterol level and atherogenicity index were significantly higher in pregnant women with MS compared to healthy ones.

Table 4 presents the comparison of MS prevalence according to sociodemographic and obstetric parameters. It shows an increase in the prevalence of MS with age of participants. Indeed, the prevalence of MS was $4.76 \%$ among participants aged under 20 years old, $14.48 \%$ among participants aged between 20-30 years old, 25.71\% among participants aged $30-40$ years old and 50\% among participants aged 40 years old and above $(p<0.0001)$. Besides,

Table 3 Metabolic Profile of Study Participants

\begin{tabular}{|l|l|l|l|l|}
\hline Parameters & General (604) & Non-MS (496) & MS (108) & $\boldsymbol{P}$ \\
\hline Pre-pregnancy BMI & $27.92 \pm 4.83$ & $26.80 \pm 4.09$ & $33.04 \pm 4.68$ & $<0.0001$ \\
SBP & $111.40 \pm 42.90$ & $110.50 \pm 46.84$ & $115.58 \pm 14.15$ & 0.043 \\
DBP & $71.66 \pm 9.86$ & $70.74 \pm 9.61$ & $75.87 \pm 9.96$ & $<0.0001$ \\
Blood glucose & $78.88 \pm 11.90$ & $78.16 \pm 10.44$ & $82.18 \pm 17.05$ & 0.020 \\
TG & $194.16 \pm 109.28$ & $181.05 \pm 103.86$ & $254.39 \pm 113.74$ & $<0.0001$ \\
TC & $195.52 \pm 83.11$ & $196.26 \pm 84.23$ & $192.15 \pm 78.07$ & 0.626 \\
HDL-C & $50.40 \pm 34.96$ & $53.27 \pm 36.55$ & $37.21 \pm 22.17$ & $<0.0001$ \\
LDL-C & $117.19 \pm 79.70$ & $117.84 \pm 80.82$ & $114.08 \pm 74.36$ & 0.660 \\
Atherogenicity index & $5.14 \pm 3.78$ & $4.94 \pm 3.77$ & $6.03 \pm 3.10$ & 0.001 \\
\hline
\end{tabular}

Note: Data are presented as mean \pm standard deviation.

Abbreviations: MS, Metabolic syndrome; BMI, Body mass index; SBP, Systolic blood pressure; DBP, Diastolic blood pressure; TG, Triglycerides; TC, Total cholesterol; HDLC, High density lipoprotein cholesterol; LDL-C, Low density lipoprotein cholesterol.

Table 4 Comparison of MS Prevalence According to Sociodemographic and Obstetric Parameters

\begin{tabular}{|c|c|c|c|c|}
\hline \multicolumn{2}{|l|}{ Parameters } & \multirow{3}{*}{$\begin{array}{l}\text { Non-MS (496) } \\
95.24(40) \\
85.52(319)\end{array}$} & \multirow{2}{*}{$\frac{\text { MS ( }(108)}{4.76(2)}$} & \multirow{2}{*}{$\frac{p}{<0.0001}$} \\
\hline Age & $<20$ & & & \\
\hline & [20-30] & & $14.48(54)$ & \\
\hline & [30-40] & $74.29(130)$ & $25.71(45)$ & \\
\hline & $\geq 40$ & $50.00(7)$ & $50.00(7)$ & \\
\hline \multirow[t]{3}{*}{ Stage of the pregnancy } & Ist Trimester & $87.18(136)$ & $12.82(20)$ & 0.154 \\
\hline & 2nd Trimester & $80.78(206)$ & $19.82(49)$ & \\
\hline & 3rd Trimester & $79.79(154)$ & 20.21 (39) & \\
\hline \multirow[t]{4}{*}{ Marital status } & Single & $87.38(187)$ & $12.62(27)$ & 0.036 \\
\hline & Divorced & $100.00(4)$ & $0.00(0)$ & \\
\hline & Cohabitation & $82.62(44)$ & $15.38(8)$ & \\
\hline & Married & $78.14(26 I)$ & $21.86(73)$ & \\
\hline \multirow[t]{4}{*}{ Level of education } & None & $92.86(13)$ & $7.14(1)$ & 0.709 \\
\hline & Primary & $78.38(29)$ & $21.62(8)$ & \\
\hline & Secondary & $81.39(223)$ & $|8.6|(5 \mid)$ & \\
\hline & Higher education & $82.80(23 I)$ & $17.20(48)$ & \\
\hline \multirow[t]{4}{*}{ Parity } & Nulliparous & $86.59(239)$ & $|3.4|(37)$ & 0.019 \\
\hline & Primiparous & $87.85(94)$ & $12.15(13)$ & \\
\hline & Multiparous & $79.29(111)$ & $20.71(29)$ & \\
\hline & Grand multiparous & $67.86(19)$ & $32.14(9)$ & \\
\hline \multirow[t]{3}{*}{ Pre-pregnancy BMI } & Normal weight & $97.79(177)$ & $2.21(4)$ & $<0.000$ I \\
\hline & Overweight & $93.44(242)$ & $6.56(17)$ & \\
\hline & Obese & $46.95(77)$ & $53.05(87)$ & \\
\hline
\end{tabular}

Note: Data are presented as relative frequencies (in \%) and absolute frequencies ( $n$ ).

Abbreviations: MS, Metabolic syndrome; BMI, Body mass index. 
the prevalence of MS was higher among married participants (21.86\%), grand multiparous (32.14\%) and obese pregnant women $(53.05 \%)$.

Influence of family history of chronic diseases, level of physical activity and lifestyle parameters on the prevalence of MS is shown in Table 5. There is no significant difference in the prevalence of MS according to family history of chronic diseases. Regarding lifestyle parameters and level of physical activity, there is a higher prevalence of MS among pregnant women consuming alcohol before or during pregnancy $(20.89 \%$ and $25.19 \%$ respectively) compared to nonconsumers (13.47\% and $15.54 \%$ respectively). Besides, the prevalence of MS tends to decrease with an increase in the duration of daily walking practice even though the difference is not significant $(p=0.058)$.

Table 6 presents the comparison of the prevalence of MS according to dietary habits. It appears from this table that some dietary habits are associated with a higher prevalence of MS, those are eating close to bedtime (19.38\%), regular consumption of soft drinks (21.62\%) and regular consumption of eggs (19.71\%). Participants eating fresh fruits over four days per week presented lower prevalence of MS (11.46\%) than those eating fresh fruits only four days or fewer a week.

Table 7 shows the results of univariate and multivariate binary logistic regression models to predict MS according to relevant independent variables of the study. It indicates that pregnant women aged 30 years or above present higher risk of having MS compared to younger ones. Concerning parity, grand multiparous shows a higher risk of presenting MS (OR:3.06, 95\% CI: $1.24-7.12 ; p=0.011$ ) compared to nulliparous. Overweight (OR: 3.11, 95\% CI:1.13-10.94; $p=0.045$ ) and obese (OR: $50.00,95 \%$ CI: $19.97-167.85 ; p<0.0001$ ) participants also present a higher risk of developing MS compared to normal weight participants. The risk of developing MS also increases with alcohol consumption before pregnancy (OR:1.70, 95\%

Table 5 Comparison of MS Prevalence According to Family History of Chronic Diseases, Level of Physical Activity and Lifestyle Parameters

\begin{tabular}{|c|c|c|c|c|}
\hline Parameters & & Non-MS (496) & MS (108) & $p$ \\
\hline \multicolumn{5}{|c|}{ Family history of chronic diseases } \\
\hline \multirow[t]{2}{*}{ Type 2 Diabetes } & Yes & $77.42(96)$ & $22.58(28)$ & 0.147 \\
\hline & No & $83.33(400)$ & $16.67(80)$ & \\
\hline \multirow[t]{2}{*}{ Cardiovascular diseases } & Yes & $76.25(61)$ & $23.75(19)$ & 0.159 \\
\hline & No & $82.92(432)$ & $17.08(89)$ & \\
\hline \multirow[t]{2}{*}{ Gestational diabetes } & Yes & $84.00(21)$ & $16.00(4)$ & 0.802 \\
\hline & No & $82.04(475)$ & $17.96(104)$ & \\
\hline \multirow[t]{2}{*}{ Pre eclampsia or eclampsia } & Yes & $85.71(12)$ & $14.29(2)$ & 0.716 \\
\hline & No & $81.94(48 I)$ & $18.06(106)$ & \\
\hline \multicolumn{5}{|c|}{ Lifestyle and Level of physical activity } \\
\hline Alcohol consumption before & Yes & $79.11(284)$ & $20.89(75)$ & 0.019 \\
\hline pregnancy & No & $86.53(212)$ & $13.47(33)$ & \\
\hline Alcohol consumption during & Yes & $74.83(110)$ & $25.17(37)$ & 0.008 \\
\hline pregnancy & No & $84.46(386)$ & I5.54 (7I) & \\
\hline \multirow[t]{2}{*}{ Physical activity } & Yes & $81.25(156)$ & $18.75(36)$ & 0.703 \\
\hline & No & $82.52(340)$ & $17.48(72)$ & \\
\hline \multirow[t]{3}{*}{ Daily walking } & $<30$ minutes & $80.26(248)$ & $19.74(61)$ & 0.058 \\
\hline & $30-60$ minutes & $83.35(210)$ & $17.65(45)$ & \\
\hline & $>60$ minutes & $95.00(38)$ & $5.00(2)$ & \\
\hline \multirow[t]{2}{*}{ Farm work } & Yes & $82.57(25 \mathrm{I})$ & $17.43(53)$ & 0.773 \\
\hline & No & $81.67(245)$ & $18.33(55)$ & \\
\hline \multirow[t]{3}{*}{ Physical activity level score } & Inactive & $82.76(240)$ & $17.24(50)$ & 0.632 \\
\hline & Active & $81.17(250)$ & $18.33(58)$ & \\
\hline & Very active & $100.00(6)$ & $0.00(0)$ & \\
\hline
\end{tabular}

Note: Data are presented as relative frequencies (in \%) and absolute frequencies (n).

Abbreviations: MS, Metabolic syndrome; BMI, Body mass index. 
Table 6 Comparison of MS Prevalence According to Dietary Habits

\begin{tabular}{|c|c|c|c|c|}
\hline \multicolumn{2}{|l|}{ Parameters } & \multirow{2}{*}{$\begin{array}{l}\text { Non-MS (496) } \\
82.84(280)\end{array}$} & \multirow{2}{*}{$\frac{\text { MS (108) }}{17.16(58)}$} & \multirow{2}{*}{\begin{tabular}{|l|}
$P$ \\
0.878
\end{tabular}} \\
\hline Number of meals per day & $\mathrm{I}-2$ & & & \\
\hline & $3-4$ & $81.10(206)$ & $18.90(48)$ & \\
\hline & $<5$ & $83.33(10)$ & $16.67(2)$ & \\
\hline \multirow{2}{*}{ Eating close to bedtime } & Yes & $80.62(391)$ & $19.38(94)$ & 0.031 \\
\hline & No & $88.24(105)$ & $11.76(14)$ & \\
\hline \multirow[t]{2}{*}{ Weekly consumption of soft drinks } & Yes & $78.38(174)$ & $21.62(68)$ & 0.043 \\
\hline & No & $84.29(33 I)$ & I5.7| (65) & \\
\hline \multirow[t]{2}{*}{ Weekly consumption of Tea or coffee } & Yes & $79.33(165)$ & $20.67(43)$ & 0.194 \\
\hline & No & $83.59(4)$ & $16.4 \mid(0)$ & \\
\hline \multirow{2}{*}{$\begin{array}{l}\text { Weekly consumption of Cakes, cookies, } \\
\text { donuts }\end{array}$} & Yes & $80.95(340)$ & $19.05(80)$ & 0.258 \\
\hline & No & $84.78(156)$ & $15.22(28)$ & \\
\hline \multirow[t]{2}{*}{ Consumption of Fresh fruits } & $<4$ days/week & $80.91(44)$ & $19.09(8)$ & 0.045 \\
\hline & $>4$ days/week & $88.54(26 I)$ & II.46 (73) & \\
\hline \multirow[t]{2}{*}{ Weekly consumption of Raw vegetables } & Yes & $82.33(396)$ & $17.67(85)$ & 0.790 \\
\hline & No & $81.30(100)$ & $18.70(23)$ & \\
\hline \multirow{2}{*}{$\begin{array}{l}\text { Weekly consumption of cooked } \\
\text { vegetables }\end{array}$} & Yes & $80.91(356)$ & $19.09(84)$ & 0.203 \\
\hline & No & $85.37(140)$ & $14.63(24)$ & \\
\hline \multirow[t]{2}{*}{ Weekly consumption of Eggs } & Yes & $80.29(334)$ & $19.7 \mid(82)$ & 0.049 \\
\hline & No & $86.17(162)$ & $13.83(26)$ & \\
\hline
\end{tabular}

Note: Data are presented as relative frequencies (in\%) and absolute frequencies (n).

Abbreviations: MS, Metabolic syndrome; BMI, Body mass index.

Table 7 Logistic Regression Models Predicting Metabolic Syndrome

\begin{tabular}{|c|c|c|c|c|c|}
\hline \multicolumn{2}{|l|}{ Explanatory Variables } & \multirow{2}{*}{$\begin{array}{c}\begin{array}{c}\text { Univariate OR } \\
(95 \% \mathrm{CI})\end{array} \\
-\end{array}$} & \multirow{2}{*}{$\begin{array}{l}p \\
-\end{array}$} & \multirow{2}{*}{$\begin{array}{c}\begin{array}{c}\text { Multivariate OR } \\
(95 \% \mathrm{CI})\end{array} \\
-\end{array}$} & \multirow{2}{*}{$\begin{array}{l}p \\
-\end{array}$} \\
\hline Age & $<20$ & & & & \\
\hline & {$[20-30]$} & $3.39(1.00-21.16)$ & 0.099 & $1.37(0.26-7.27)$ & 0.710 \\
\hline & {$[30-40]$} & $6.92(2.01-43.57)$ & 0.009 & $\mathrm{I} .3 \mathrm{I}(0.22-7.8 \mathrm{I})$ & 0.764 \\
\hline & $\geq 40$ & $20.00(3.94-155.09)$ & 0.001 & $2.11(0.17-26.20)$ & 0.562 \\
\hline \multirow[t]{4}{*}{ Parity } & Nulliparous & - & - & - & - \\
\hline & Primiparous & $0.89(0.44-1.72)$ & 0.743 & $0.53(0.26-1.23)$ & 0.136 \\
\hline & Multiparous & $1.69(0.98-2.88)$ & 0.056 & $1.00(0.47-2.14)$ & 0.991 \\
\hline & Grand multiparous & $3.06(1.24-7.12)$ & 0.011 & $0.94(0.26-3.36)$ & 0.927 \\
\hline \multirow[t]{3}{*}{ Pre-pregnancy BMI } & Normal weight & - & - & - & - \\
\hline & Overweight & $3.11(1.13-10.94)$ & 0.045 & $2.69(0.86-8.44)$ & 0.090 \\
\hline & Obese & $50.00(19.97-167.85)$ & $<0.0001$ & 46.46 (I5.58-138.49) & $<0.0001$ \\
\hline Alcohol consumption & Yes & $1.70(1.09-2.68)$ & 0.020 & $1.00(0.50-1.94)$ & 0.979 \\
\hline before pregnancy & No & - & - & - & - \\
\hline Alcohol consumption & Yes & $1.83(1.16-2.86)$ & 0.009 & $0.76(0.36-1.56)$ & 0.463 \\
\hline during pregnancy & No & - & - & - & - \\
\hline \multirow[t]{3}{*}{ Daily walking } & $<30$ minutes & - & - & - & - \\
\hline & $30-60$ minutes & $0.87(0.57-1.33)$ & 0.527 & $1.04(0.58-1.87)$ & 0.889 \\
\hline & $>60$ minutes & $0.21(0.03-0.73)$ & 0.037 & $0.24(0.03-2.08)$ & 0.195 \\
\hline \multirow[t]{2}{*}{ Eating close to bedtime } & Yes & $1.80(1.02-3.42)$ & 0.055 & $1.85(0.83-4.16)$ & 0.133 \\
\hline & No & - & - & - & - \\
\hline Weekly consumption of soft & Yes & $1.48(0.97-2.26)$ & 0.068 & $1.59(0.88-2.88)$ & 0.128 \\
\hline drinks & No & - & - & - & - \\
\hline Weekly Consumption of & $<4$ days/week & - & - & - & - \\
\hline fresh fruits & $>4$ days/week & $0.55(0.27-1.03)$ & 0.077 & $0.74(0.3|-| .77)$ & 0.498 \\
\hline \multirow[t]{2}{*}{ Weekly consumption Eggs } & Yes & $1.53(0.96-2.5 \mathrm{I})$ & 0.082 & $1.53(0.78-2.98)$ & 0.217 \\
\hline & No & - & - & - & - \\
\hline
\end{tabular}

Abbreviations: OR, Odd ratio; $\mathrm{Cl}$, Confidence interval. 
CI: $1.09-2.68 ; p=0.020)$ and alcohol consumption during pregnancy (OR:1.83, 95\% CI: 1.16-2.86; $p=0.009$ ), while it significantly decreases with at least 60 minutes of daily walking (OR: $0.21,95 \% \mathrm{CI}: 0.03-0.73 ; p=0.037$ ).

\section{Discussion}

The present study aimed to determine the prevalence of Metabolic Syndrome and associated factors among pregnant women in the Dschang health district in the west region of Cameroon. The prevalence of MS in the study population was 17.88\% (95\% CI: 15.03-21.14). Similar result was obtained by Grieger et al among nulliparous pregnant women recruited in the UK, New Zealand and Australia, but lower prevalence was obtained by Djeufouata et al in the littoral and center regions of Cameroon. ${ }^{21,22}$ The relatively high prevalence of MS observed in the present study, can be attributed to the definition criteria that vary from one study to another, but also to a higher prevalence of pre-gestational obesity in our study which appears to be the major determinant of MS during pregnancy. ${ }^{22}$ Indeed, our study took place in the west region of Cameroon, where the prevalence of obesity is among the highest in the country, and overweight considered as a sign of wellbeing. ${ }^{9}$

Among individual components of MS, low levels of HDL-cholesterol (66.23\%; 95\% CI: 62.36-69.88) and hypertriglyceridemia (58.28\%; 95\% CI: 54.31-62.15) were the most frequent in the study population. Pinto et al found a strong association between MS and HDL-cholesterol levels even after adjustment on other parameters, suggesting a tight relationship between low HDL-cholesterol blood levels and the physiopathology of MS during pregnancy. ${ }^{23}$ Grieger et al, ${ }^{21}$ in their study in Australia, also found hypertriglyceridemia to be the most common component of MS among pregnant women. This predominance of hypertriglyceridemia and low levels of HDL-cholesterol may be the consequence of impaired insulin sensitivity related modifications in triglycerides metabolism. Indeed, the amount of circulating triglycerides increases with gestational age, transported through lipoproteins. ${ }^{24,25}$ Authors have reported that an enrichment of HDL with triglycerides was associated with a greater clearance of HDL, leading to low levels of HDL-cholesterol. ${ }^{26}$

The comparison of our study participants' metabolic profile shows a significant increase of pre-gestational BMI, SBP, DBP, triglycerides, blood glucose levels, atherogenicity index and a significant decrease of HDL-cholesterol in pregnant women with MS compared to healthy ones (Table 3). These results are similar to those of dos Prazeres et al and Djeufouata et $\mathrm{al}^{22,27}$ and paint a picture of a MS related degradation of pregnant women's metabolism with alteration of different metabolic pathways mostly driven by impaired insulin sensitivity. ${ }^{28}$

The comparison of MS prevalence according to sociodemographic and obstetric parameters shows a significant increase of the prevalence of MS with age of participants. There is a higher prevalence of MS among married participants compared to participants with other marital status; the prevalence of MS is also higher among multiparous and grand multiparous compared with pauciparous (Table 4). Associations between age, parity and MS are strengthened by the results of univariate binary logistic regression which showed that pregnant women aged 30 years or above present higher risk of having MS compared to younger ones (Table 7) and grand multiparous shows higher risk of developing MS (OR: 3.06, 95\% CI: $1.24-7.12 ; p=0.011)$ compared to nulliparous. These results draw nigh to the results of dos Prazeres et al who found significant associations between age, parity and MS in Angolan pregnant women. ${ }^{27}$ Age is a well-known risk factor for an extensive set of chronic diseases, including obesity and metabolic syndrome. ${ }^{2}$ Besides, several authors have shown that multiparous women have higher risk of developing metabolic syndrome; this may be associated with the proven correlation between multiparity and the development of abdominal obesity that leads to adipose tissue mediated dysregulation of insulin sensitivity and other metabolic pathways. ${ }^{29-31}$

In this study, we found no significant association between the prevalence of MS and family history of chronic diseases (Table 5). This result is consistent with the review of Saklayen, presenting evidence that genetic predisposition may play minor role in the development of MS despite the existence of some genes associated to obesity and MS. On the contrary, epigenetics may have a bigger role promoting MS. ${ }^{2}$

Regarding lifestyle parameters and level of physical activity, there is higher prevalence of MS among pregnant women consuming alcohol before or during pregnancy while the prevalence tends to decrease with an increase in the duration of daily walking practice (Table 5). These results are confirmed by the logistic regression. Indeed, the risk of developing MS increases with alcohol consumption before pregnancy (OR:1.70, 95\% CI: $1.09-2.68 ; p=0.020$ ) and alcohol consumption during pregnancy (OR:1.83, 95\% CI: 1.16-2.86; $p=0.009)$, while it significantly decreases with at 
least 60 minutes of daily walking (OR: $0.21,95 \%$ CI: $0.03-0.73 ; p=0.037$ ). Previous studies have reported an association between alcohol consumption and MS on various subpopulations, including pregnant women. ${ }^{32,33}$ Even though the role of alcohol consumption in triggering the development of MS remains controversial, evidences suggest that moderate to high alcohol consumption levels lead to hypertriglyceridemia, inhibition of lipid oxidation in adipose tissue and fat storage. ${ }^{34,35}$

Concerning physical activity, our results suggest that moderate but consistent daily effort may lower the risk of developing MS on pregnant women. This is not in accordance with previous study that reported inverse association between MS and vigorous but not low and moderate exercise. ${ }^{22}$ Nonetheless, there are evidences that chronic exercise presents benefits on MS by promoting energy balance, but also by triggering healthy physiological modifications in muscles cells and tissues. ${ }^{2}$

It appears from this study that some dietary habits including eating close to bedtime, regular consumption of soft drinks and regular consumption of eggs are associated with a higher prevalence of MS, while eating fresh fruits over four days per week is associated with a lower prevalence of MS (Table 6). These results add supporting evidence of nutritional transition in Cameroonian populations with progressive abandon of traditional dietary habits to westernized diet and lifestyle with consequences on metabolic health, as previously reported. ${ }^{32,33}$

Binary logistic regression models were performed in this study, to identify predictors of MS among its individual components and relevant independent variables (Tables 2 and 7). Pre-gestational obesity appears as the best predictor of MS during pregnancy even after adjustment on age, parity, lifestyle and dietary habits. Indeed, pre-gestational BMI have been previously reported as the major component of MS during pregnancy. ${ }^{22,23}$ Pre-gestational obesity may contribute to a worsening of metabolic profile alteration on pregnant women, leading to a higher risk of developing MS.

\section{Strength and Limitations}

This study is among the first to address the prevalence and factors associated with MS during pregnancy in the west region of Cameroon and provide quality preliminary data for the design and improvement of prevention strategies. Moreover, The Dschang District Hospital is the major health facility in the Dschang health district and that guarantee a good representativity of the study sample. However, there is no standardized definition of MS for pregnant women and the definition considered in this study may leads to an overestimation of its prevalence. Besides, some of the findings may be subjected to measure bias due to self-reported information that may be altered by recall bias.

\section{Conclusion}

The prevalence of MS on pregnant women in the Dschang health district is $17.88 \%$ (95\% CI: 15.03-21.14) majorly determined by pregestational obesity. Interventions then needs to targets women of reproductive age. This work provides a valuable starting point for further studies in the region and the country, for the setting of dietary and clinical recommendations that may contribute to a better prevention of MS during pregnancy as well as its maternal and perinatal adverse outcomes.

\section{Abbreviations}

HNLBI/AHA, National Heart, Lung and Blood Institute/American Heart Association; NCEP ATP III, National Cholesterol Education Program, Expert Panel on Detection, Evaluation, and Treatment of High Blood Cholesterol in Adults; HDL-C, High-density lipoprotein cholesterol; MS, Metabolic syndrome; TG, Triglyceride.

\section{Data Sharing Statement}

The datasets used and/or analyzed during the current study are available from the corresponding author on reasonable request.

\section{Acknowledgments}

Authors kindly acknowledge the laboratory and antenatal consultation staff of the Dschang District Hospital as well as all the pregnant women enrolled in the study. 


\section{Disclosure}

The authors report no conflicts of interest in this work.

\section{References}

1. Alberti KG, Eckel RH, Grundy SM, et al. Harmonizing the metabolic syndrome a joint interim statement of the international diabetes federation taskforce on epidemiology and prevention; national heart, lung, and blood institute; American heart association; world heart federation; international atherosclerosis society; and international association for the study of obesity. Circ. 2009;120:1640-1645.

2. Saklayen MG. The global epidemic of metabolic syndrome. Curr Hypertens Rep. 2018;20:12. doi:10.1007/s11906-018-0812-z

3. Bo L, Guanqun C, Ruijie Z, Huang D, Tao L, Dan H and Lixin T. Temporal trends in the prevalence of metabolic syndrome among middle-aged and elderly adults from 2011 to 2015 in China: the China health and retirement longitudinal study (CHARLS). BMC Public Health. 2021;21:1045. doi:10.1186/s12889-021-11042-x

4. Harikrishnan S, Sarma S, Sanjay G, et al. Prevalence of metabolic syndrome and its risk factors in Kerala, South India: analysis of a community based cross-sectional study. PLoS One. 2018;13(3):e0192372. doi:10.1371/journal.pone.0192372

5. Kaduka LU, Kombe Y, Kenya E, et al. Prevalence of metabolic syndrome among an urban population in Kenya. Diabetes Care. 2012;35:887-893. doi:10.2337/dc11-0537

6. Ben-Yacov L, Ainembabazi P, Stark AH, et al. Prevalence and sex specific patterns of metabolic syndrome in rural Uganda. BMJ Nutr Prev Health. 2020;3:e00050.

7. Sintayehu A, Aklilu E, Abebaw W, Yalewayker T, Mulugeta M, Belete B. The prevalence of metabolic syndrome in Ethiopian population: a systematic review and meta-analysis. J Obes. 2020. doi:10.1155/2020/2701309

8. Kruger MJ, Nell TA. The prevalence of the metabolic syndrome in a farm worker community in the Boland district, South Africa. Public Health. 2017;17:61. doi:10.1186/s12889-016-3973-1

9. Marbou WJ, Kuete V. Prevalence of metabolic syndrome and its components in Bamboutos division's adults, West Region of Cameroon. Biomed Res Int. 2019;2019:1-12. ID 9676984. doi:10.1155/2019/9676984

10. Vryonidou A, Paschou SA, Muscogiuri G, Orio F, Goulis DG. Mechanisms in endocrinology: metabolic syndrome through the female life cycle. Eur J Endocrinol. 2015;173:R153-R163. doi:10.1530/EJE-15-0275

11. Dos Prazerez TH, Arantes AM, Tavares SB, et al. Metabolic syndrome and pregnancy, its prevalence, obstetrical and newborns complications. Open J Obstet Gynecol. 2015;5(11):618-625. doi:10.4236/ojog.2015.511087

12. Chatzi L, Plana E, Pappas A, et al. The metabolic syndrome in early pregnancy and risk of gestational diabetes mellitus. Diabetes Metab. 2009;35 (6):490-494. doi:10.1016/j.diabet.2009.07.003

13. Chatzi L, Plana E, Daraki V, et al. Metabolic syndrome in early pregnancy and risk of preterm birth. Am J Epidemiol. 2009;170(7):829-836. doi:10.1093/aje/kwp211

14. Ray JG, Thompson MD, Vermeulen MJ. Metabolic syndrome features and risk of neural tube defects. BMC Pregnancy Childbirth. $2007 ; 7: 21$. doi:10.1186/1471-2393-7-21

15. Mohsenzadeh-Ledari F, Taghizadeh Z, Motaghi Z, Keramat A, Moosazadeh M, Najafi A. Appropriate interventions for pregnant women with indicators of metabolic syndrome on pregnancy outcomes: a systematic review. Int J Prev Med. 2019;10:2. doi:10.4103/ijpvm.IJPVM_46_18

16. Matene FE. Etude Du Gain Pondéral Excessif Pendant la Grossesse et de son Influence sur le Développement Du Syndrome Métabolique Chez Les Femmes Enceintes Suivies à l'hôpital de District de Dschang [Study of excessive weight gain during pregnancy and its influence on the development of metabolic syndrome on pregnant women followed-up at the Dschang District Hospital] [Dissertation]. Dschang: University of Dschang; 2017. French.

17. World Health Organisation. Obesity: Preventing and managing the global epidemic. Technical report. Geneva, Switzerland; 2003.

18. Fossati P, Principe L. Triglycérides PAP, freeze dried. Clin Chem. 1982;28:2077. doi:10.1093/clinchem/28.10.2077

19. Trinder P. Determination of glucose in blood using glucose oxidase with alternative oxygen acceptor. Annu Clin Biochem. 1969;6:24-27. doi:10.1177/000456326900600108

20. Friedewald WT, Levy RI, Fredrickson DS. Estimation of the concentration of low-density lipoprotein cholesterol in plasma, without use of the preparative ultracentrifuge. Clin Chem. 1972;18:499-502. doi:10.1093/clinchem/18.6.499

21. Grieger JA, Bianco-Miotto T, Grzeskowiak LE, et al. Metabolic syndrome in pregnancy and risk for adverse pregnancy outcomes: a prospective cohort of nulliparous women. PLoS Med. 2018;15(12):e1002710. doi:10.1371/journal.pmed.1002710

22. Djeufouata JD, Ojong EW, Njamen NT, Assob JC, Telefo PB. Prevalence and risk factors of metabolic syndrome in pregnant women in the centre and littoral regions of Cameroon. Eur J Clin Bioimed Sci. 2020;6(5):104-115. doi:10.11648/j.ejcbs.20200605.16

23. Pinto MC, Oliveira AS, Santos AS, De oliveira BV, Ramos MM. Metabolic syndrome in pregnancy and postpartum: prevalence and associated factors. Rev Assoc Med Bras. 2019;65(12):1489-1495. doi:10.1590/1806-9282.65.12.1489

24. Jacovetti C, Regazzi R. Adaptations métaboliques au cours de la grossesse [Metabolic adaptations during pregnancy]. Méd des Mal Métab. 2012;6 (4):279-287. French.

25. Wani K, Sabico S, Alnaami AM, et al. Early-pregnancy metabolic syndrome and subsequent incidence in gestational diabetes mellitus in Arab women. Front Endocrinol. 2020;11:98. doi:10.3389/fendo.2020.00098

26. Richard C. Étude des Mécanismes Responsables des Effets Bénéfiques de la Diète MÉDITERRANÉENNE, Avec et sans Perte de Poids, Chez des Hommes Avec le Syndrome Métabolique[Study of the mechanisms responsible for the beneficial effects of the Mediterranean diet, with and without weight loss, in men with metabolic syndrome] [Thesis]. Laval: University of Laval; 2013. French.

27. dos Prazeres TH, Damasceno DC, Dos santos M, et al. Prevalence of metabolic syndrome in non-diabetic, pregnant Angolan women according to four diagnostic criteria and its effects on adverse perinatal outcomes. Diabetol Metab Syndr. 2016;8(27):22. doi:10.1186/s13098-016-0134-8

28. Nolan CJ, Prentki M. Insulin resistance and insulin hypersecretion in the metabolic syndrome and type 2 diabetes: time for a conceptual framework shift. Diab Vasc Dis Res. 2019;16(2):118-127. doi:10.1177/1479164119827611 
29. Baguma M, Ilimbizi B, Katchunga P. Parité et risque du syndrome métabolique chez la femme congolaise du Sud-Kivu, République Démocratique du Congo [Parity and risk of metabolic syndrome in Congolese women in South Kivu, Democratic Republic of Congo]. Obesity. 2014;9:293-298. French.

30. Yao Y, Liu HM, Wang XW, et al. Effect of body mass index on the associations between parity and metabolic syndrome and its components among Northern Chinese women. Biomed Environ Sci. 2020;33(1):11-18. doi:10.3967/bes2020.002

31. Vladutiu CJ, Siega-Riz AM, Sotres-Alvarez D, et al. Parity and components of the metabolic syndrome among U.S. Hispanic/Latina women: results from the HCHS/SOL study. Circ Cardiovasc Qual Outcomes. 2016;9(2 Suppl 1):S62-S69. doi:10.1161/CIRCOUTCOMES.115.002464

32. Dabou S, Telefo PB, Sama FL. Evaluation of dietary habits and lifestyle on the prevalence of metabolic syndrome and obesity in undergraduate university students in Cameroon: a cross sectional study. J Metabolic Synd. 2018;7:1. doi:10.4172/2167-0943.1000236

33. Djeufouata JD, Ojong EW, Njamen NT, Assob JC, Telefo PB. Association between lifestyle factors, eating habits and metabolic syndrome in Cameroonian pregnant women. WJPH. 2021;9(1):7-15.

34. Kwak SM, Choi MR, Bang SH, et al. Prevalence Risk of metabolic syndrome associated with alcohol use behavior in Korean women. Psychiatry Investig. 2018;15(2):219-225. doi:10.30773/pi.2017.05.12

35. Clerc O, Nanchen D, Cornuz J, et al. Alcohol drinking, the metabolic syndrome and diabetes in a population with high mean alcohol consumption. Diabet Med. 2010;27:1241-1249. doi:10.1111/j.1464-5491.2010.03094.x

Diabetes, Metabolic Syndrome and Obesity: Targets and Therapy

\section{Publish your work in this journal}

Diabetes, Metabolic Syndrome and Obesity: Targets and Therapy is an international, peer-reviewed open-access journal committed to the rapid publication of the latest laboratory and clinical findings in the fields of diabetes, metabolic syndrome and obesity research. Original research, review, case reports, hypothesis formation, expert opinion and commentaries are all considered for publication. The manuscript management system is completely online and includes a very quick and fair peer-review system, which is all easy to use. Visit http://www.dovepress. com/testimonials.php to read real quotes from published authors.

Submit your manuscript here: https://www.dovepress.com/diabetes-metabolic-syndrome-and-obesity-targets-and-therapy-journal 